Results Overall, 174 women were studied at a mean gestational age of $15.3 \pm 3.0$ weeks (early pregnancy) and home sleep testing was repeated at a mean gestational age of 35.5 \pm 1.9 weeks (late pregnancy). Sleep duration decreased as pregnancy progressed $(6.8 \mathrm{hr}$ vs $6.0 \mathrm{hr}, \mathrm{p}<0.001)$ while both the $\mathrm{AHI}$ and the oxygen desaturation index increased $(2.2 \mathrm{vs.}$ $5.4, \mathrm{p}<0.001$ and 0.5 vs $1.8, \mathrm{p}<0.001$ respectively). The proportion of women spending some time in the supine sleep position was $36 \%$ in early pregnancy, rising to $50 \%$ in late pregnancy $(p=0.03)$. of note, $16 \%$ of women spent at least half the night supine in early pregnancy and $20 \%$ of women did so in late pregnancy.

Discussion Half of women spend some time in the supine sleep position in late pregnancy. Given the emerging associations between supine sleep and stillbirth, maternal sleep practices offer a modifiable risk factor.

\section{DEPRESSIVE SYMPTOMS IN PREGNANCY: THE ROLE OF SLEEP TIMING}

Louise O’Brien*, Anna Olsen, David Kalmbach, Helen Burgess, Leslie Swanson. University of Michigan, Ann Arbor, USA, Henry Ford Health System, Detroit, USA

\subsection{6/bmjresp-2021-bssconf.36}

Introduction Insufficient and disrupted sleep in pregnancy is significantly associated with antenatal and postnatal depression, which affects up to $20 \%$ of perinatal women. Sleep timing is another important sleep variable that represents sleep preferences besides sleep duration, and mid-point of sleep strongly correlates with chronotype and dim light melatonin onset. In the general population delayed sleep mid-point contributes to poor cardiometabolic and psychological function. Emerging data in pregnancy suggest that later sleep mid-point is related to gestational diabetes, gestational hypertension and preeclampsia. However, it is currently unknown whether sleep timing plays a role in depressive symptoms in pregnancy.

Methods Pregnant women at least 28 weeks' gestation were recruited from a large academic medical centre and invited to complete surveys about their sleep, including typical bedtimes and wake-times, as well as demographic information. Presence of depressive symptoms was determined by a current diagnosis of depression or a score $\geq 10$ on the Edinburgh Postnatal Depression Scale (EPDS). Sleep mid-point was calculated as halfway between sleep onset and rise time.

Results Overall, 1599 women were included, of which 30\% had depressive symptoms. Demographics are shown in table 1. Women with depressive symptoms had similar bedtimes to

Abstract 41 Table 1

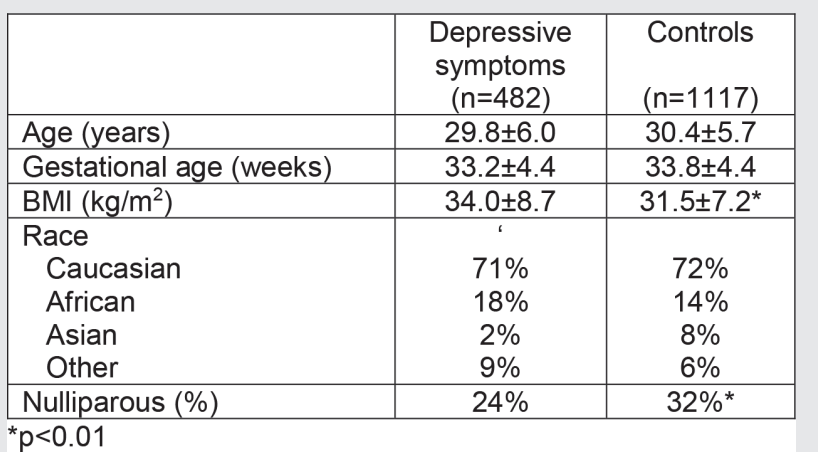

controls $(11: 00 \mathrm{pm}$ vs. $10: 54 \mathrm{pm}, \mathrm{p}<0.17)$ but longer time in bed $(8.9 \mathrm{hr}$ vs. $8.6 \mathrm{hr}, \mathrm{p}=0.04)$. Mid-point was significantly later in women with depressive symptoms compared to controls $(03: 28 \mathrm{hr}$ vs. 03:14hr, $\mathrm{p}=0.005)$. In a regression adjusting for sleep duration and BMI, mid-point was significantly associated with depressive symptoms with an adjusted odds of 1.12 (95\%CI 1.1-1.2).

Discussion This study provides initial evidence of a link between self-reported late sleep midpoint and depressive symptoms in pregnancy. These findings suggest that sleep timing is important for maternal health and further studies investigating the potential role of chronotype and circadian timing in perinatal depression should be explored.

\section{FREQUENCY AND SEVERITY OF OBSTRUCTIVE SLEEP APNEA IN BLACK COMPARED TO WHITE PREGNANT WOMEN}

${ }^{1}$ Louise O'Brien*, ${ }^{2}$ Maristella Lucchini, ${ }^{1}$ Fanny Johns, ${ }^{1}$ Galit Dunietz, ${ }^{3}$ Kaylin White, ${ }^{4}$ David Kalmbach, ${ }^{4} D^{\prime}$ Angela Pitts. ${ }^{1}$ University of Michigan, Ann Arbor, USA; ${ }^{2}$ Columbia University, New York, USA; ${ }^{3}$ Emory University, Atlanta, USA; ${ }^{4}$ Henry Ford Health System, Detroit, USA

\subsection{6/bmjresp-2021-bssconf.37}

Introduction Black individuals experience a higher prevalence of sleep disruption, including obstructive sleep apnoea (OSA), compared to Whites, which is believed to contribute to a higher incidence of cardiovascular disease. Among pregnant women, Blacks experience a higher burden of poor pregnancy outcomes such as gestational hypertension, pre-eclampsia, gestational diabetes, foetal growth restriction, and premature birth. In pregnancy, OSA has been associated with the latter adverse outcomes. Nonetheless, it is currently unknown whether differences exist in the presence and severity of OSA between Black and White pregnant women

Methods Pregnant women in mid-to-late pregnancy were recruited from a large academic medical centre and invited to undergo home sleep testing using the WatchPAT device. OSA was defined as an apnoea-hypopnoea index (AHI) $\geq 5$ events/ hour. The frequency and severity of OSA was compared between Black and White pregnant women.

Results 191 women enrolled (42 Black). Demographic information is shown in table 1. Sleep duration was shorter in Blacks compared to Whites $(350$ minutes vs 375 minutes,

Abstract 42 Table 1
\begin{tabular}{|l|c|c|}
\hline & $\begin{array}{c}\text { Black } \\
(\mathrm{n}=42)\end{array}$ & $\begin{array}{c}\text { White } \\
(\mathrm{n}=149)\end{array}$ \\
\hline Median Age (years) & $30(18-42)$ & $32(20-45)$ \\
\hline $\begin{array}{l}\text { Median Gestational Age } \\
(\text { weeks })\end{array}$ & $33(17-39)$ & $36(17-39)^{*}$ \\
\hline $\begin{array}{l}\text { Median Pre-pregnancy BMI } \\
\left(\mathrm{kg} / \mathrm{m}^{2}\right)\end{array}$ & $34(17-63)$ & $26(17-65)^{*}$ \\
\hline $\begin{array}{l}\text { Pre-pregnancy Obesity } \\
\left(\geq 30 \mathrm{~kg} / \mathrm{m}^{2}\right)(\%)\end{array}$ & $71 \%$ & $31 \%{ }^{*}$ \\
\hline $\begin{array}{l}\text { Median BMl at Sleep Study } \\
\left(\mathrm{kg} / \mathrm{m}^{2}\right)\end{array}$ & $38(22-64)$ & $30(21-70)^{*}$ \\
\hline $\begin{array}{l}\text { Obesity at Sleep Study } \\
\left(\geq 30 \mathrm{~kg} / \mathrm{m}^{2}\right)(\%)\end{array}$ & $90 \%$ & $49 \%{ }^{*}$ \\
\hline Nulliparous $(\%)$ & $41 \%$ & $43 \%{ }^{*}$ \\
\hline $\begin{array}{l}\text { Hypertensive Disorders of } \\
\text { Pregnancy }(\%)\end{array}$ & $46 \%$ & $18 \%{ }^{*}$ \\
\hline *p $<0.01$
\end{tabular}

